\title{
Design and Implementation of an Automatic Soil Moisture Sensor Irrigation System
}

\author{
Dr. Amit Gangopadhyay \\ Professor, Department of ECE, TKRCET, Hyderabad, India, amitgangopadhyay@tkrcet.com
}

\begin{abstract}
As India is an agriculture oriented country and the rate at which water resources are depleting is a dangerous threat hence there is a need of smart and efficient way of irrigation. At present most of the farmers have been using irrigation techniques through the manual control in which the farmers irrigate the land at the regular intervals. This process sometimes consumes more water or sometimes the water reaches late due to which the crops get dried. Over-irrigation can increase energy consumption and water cost as well as leaching of fertilizers below the root zone, erosion, and transport of soil and chemical particles to the drainage ditches. Irrigators who monitor soil moisture levels in the field greatly increase their ability to conserve water and energy, optimize crop yields, and avoid soil erosion and water pollution. This paper described to provide an automatic irrigation system using AT89S51 microcontroller, thereby saving time, money \& power of the farmer. With this automated technology of irrigation the human intervention can be minimized. This system is best suited for places where water is scarce and has to be used in limited quantity.
\end{abstract}

Key words : Irrigation, microcontroller, switches, soil moisture sensor.

\section{INTRODUCTION}

India's major source of income is from agriculture sector and $70 \%$ of farmers and general people depend on the agriculture [1]. Most of the irrigation systems are operated manually. These outmoded techniques are replaced with semi-automated and automated techniques. The available traditional techniques are like ditch irrigation, terraced irrigation, drip irrigation, sprinkler system. The global irrigation scenario is categorized by increased demand for higher agricultural productivity, poor performance and decreased availability of water for agriculture. These problems can be appropriately rectified if we use automated system for irrigation.

Due to increased agriculture productivity through irrigated land is being developed in arid and sub- humid zones. Agriculture has started to compete for water use with industries and other sectors. This increasing demand along with increments in water and energy costs have made it necessary to develop new technologies for the adequate management of water [2]-[4].

Irrigation is the artificial application of water to the land or soil. It is used to assist in the growing of agricultural crops, maintenance of landscapes, and re vegetation of disturbed soils in dry areas and during periods of inadequate rainfall [5],[6]. When a zone comes on, the water flows through the lateral lines and ultimately ends up at the irrigation emitter (drip) or sprinkler heads. Many sprinklers have pipe thread inlets on the bottom of them which allows a fitting and the pipe to be attached to them. The sprinklers are usually installed with the top of the head flush with the ground surface. When the water is pressurized, the head will pop up out of the ground and water the desired area until the valve closes and shuts off that zone. Once there is no more water pressure in the lateral line, the sprinkler head will retract back into the ground. Emitters are generally laid on the soil surface or buried a few inches to reduce evaporation losses [7].

The main objective of irrigation is to provide plants with sufficient water to prevent stress that may reduce the yield. The frequency and quantity of water depends upon local climatic conditions, crop and stage of growth, and soil-moisture plant characteristics. Need for irrigation can be determined in several ways that do not require knowledge of evapotranspiration (ET) rates [8]. One way is to observe crop indicators such as change of color or leaf angle, but this information may appear too late to avoid reduction in the crop yield or quality. Other similar methods of scheduling include determination of the plant water stress, soil moisture status, or soil water potential. High frequency irrigation systems involve fastidious planning and complex designs, so that timely and accurate additions of water and fertilizer can result in sustainable irrigation. At the same time these production systems are becoming more intensive, in an effort to optimize the return on expensive and scarce resources such as water and nutrients [9].

The increasing world population has lead to exponential increase in food demand. This event has necessitated the need for more land to be cultivated. Due to change of weather patterns brought about by global warming, irrigation remains as the only reliable method of crops production. With more and more land now being under irrigation there is a need for optimal use of water [10]. 
Over the last few years knowledge in electronics and computation has been used to solve present day challenges. In the forefront of the electronics revolution has been the microcontroller. The microcontroller has been used together with various sensors to measure and control physical quantities like temperature, humidity, heat and light. By controlling these physical quantities using the microcontroller; automatic systems have been achieved [11]. Irrigation systems in crop production can and has also been automated [12]. This solves the challenge brought about by the unreliability of climate changes thus need for water optimization. Automation of the soil moisture sensor irrigation systems is one of the most convenient, efficient and effective method of water optimization [13], [14]. The systems helps in saving water and thus more land can be brought under irrigation. Crops grown under controlled conditions tend to be healthier and thus give more yields. Controlled watering system results in reduction of fertilizer use and thus fertilizer costs go down.

In this paper automatic irrigation system on sensing soil moisture is intended for the development of an irrigation system that switches submersible pumps on or off by using relays to perform this action on sensing the moisture content of the soil.

\section{DESIGN AND IMPLEMENTATION}

The proposed system has three major parts: Moisture sensing part, control section and the output section. The soil moisture was detected using YL-69 soil sensor (a resistance type sensor). The control unit was achieved using microcontroller. The output was the unit used to control the irrigation system by switching it on and off depending on the soil moisture contents. Here AT89S51 microcontroller is connected to the motor driver, and the driver to the water pump. The motor can be driven by 230 volt. The moisture sensor measures the level of moisture in the soil and sends the signal to the microcontroller if watering is required. The motor/water pump supplies water to the plants until the desired moisture level is reached. Water tank level sensor controls the level of water and LM 35 temperature sensor is used to measure temperature with an electrical output proportional to the temperature $\left(\mathrm{in}^{\circ} \mathrm{C}\right)$. Two stages design were undertaken: Hardware and Software. Hardware implementation deals in drawing the schematic on the plane paper according to the application, testing the schematic design over the breadboard using the various IC's to find if the design meets the objective, carrying out the PCB layout of the schematic tested on breadboard, finally preparing the board and testing the designed hardware.

The firmware part deals in programming the microcontroller so that it can control the operation of the IC's used in the implementation. In the present work, we have used the proteus design software for PCB circuit design, the Keil Compiler development tool to write and compile the source code, which has been written in the $\mathrm{C}$ language. The Flash magic programmer has been used to write this compile code into the microcontroller. The basic block diagram of this system is shown in figure 1 .

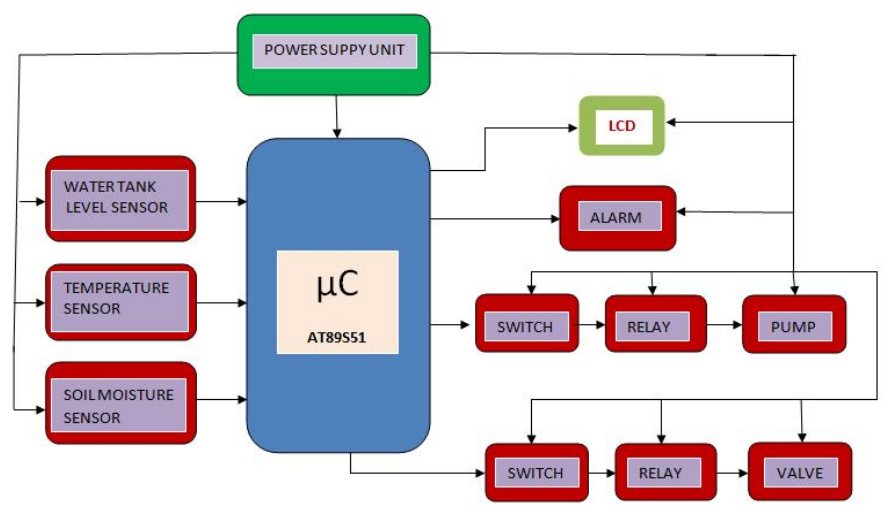

Figure1: Block Diagram of a Proposed System

In moisture sensing part soil moisture sensor reads the moisture content around it. When you submit your final version, after your paper has been In moisture sensing part soil moisture sensor reads the moisture content around it. A current is passed across the electrodes through the soil and the resistance to the current in the soil determines the soil moisture. If the soil has more, water resistance will be low and thus more current will pass through. On the other hand when the soil moisture is low the sensor module outputs a high level of resistance. This sensor has both digital and analogue outputs. Digital output is simple to use but is not as accurate as the analogue output. The soil moisture sensor is often sensing devices embedded within some sort of insulation. The insulation may often be for electrical purposes - to isolate the sensor electrically. It gives a voltage output corresponding to the conductivity of the soil. The conductivity of soil varies depending upon the amount of moisture present in it. It increases with increase in the water content of the soil. The higher the water contents of the blocks, the lower the electrical resistance. The voltage output is taken from the output terminal of this circuit. The moisture sensor is immersed into the specimen soil whose moisture content is under test. Generally a soil moisture sensor is a device that measures the volumetric water content (VWC) of soil. Mathematically VWC $(\theta)$ is given in equation (1) as follows:

$$
\theta=\frac{W_{w}}{V_{T}}
$$

Where: $\mathrm{V}_{\mathrm{w}}$ is the water volume and $\mathrm{V}_{\mathrm{T}}$ is the total volume (soil volume + water volume). Soil moisture sensors are classified according to how they measure the soil moisture content. Two methods are used in determining the volumetric water content (VWC); direct and indirect. The direct method entails drying a known volume of soil in an oven and weighing it. The direct method of measuring VWC is done using the following mathematical notation:

$$
\theta=\frac{M_{w a t}-M_{a r y}}{\rho_{W} V_{b}}
$$


Where:

a) $\mathrm{M}_{\text {wet }}$ is soil sample before drying in the oven

b) $M_{\text {dry }}$ is soil sample after drying in the oven

c) $\rho_{\mathrm{W}}$ is water density

d) $V_{b}$ is the volume of soil sample before

Soil moisture sensor was interfaced to the microcontroller through a digital a PCB drive. The PCB drive has a digital potentiometer. The digipot is used to alter the sensitivity of the sensor when connected in digital mode. The analogue configuration was selected as its more stable compared to the digital configuration. The output of the soil moisture sensor is resistance. The resistance to flow of current between the sensor probes changes with soil moisture level and soil type. The current passing through the sensor probes ( $\mathrm{I}_{\mathrm{out}}$ ) for different soils and different soil moisture levels has been calculated as $\mathrm{I}_{\mathrm{out}}=\frac{\mathrm{V}_{\mathbf{c}}}{\boldsymbol{R}_{\boldsymbol{g}}}$ where $\mathrm{R}_{\mathrm{S}}$ is the soil resistance value.

The relay switching is an electromagnetic switch which is activated when a current is applied to it. A relay uses small currents to switch huge currents. Most of the relays use principle of electromagnetism to operate but still other operating principles like solid state are also used. A contactor is a type of relay which can handle a high power required to control an electric motor or other loads directly. Solid state relays have no moving parts and they use semiconductor devices to perform switching. A relay switches has one or more poles, each of whose contacts can be thrown by energizing the coil in one of three ways:

(1) NO contacts connect the circuit when the relay is activated; the circuit is disconnected when the relay is inactive

(2) NC contacts disconnect the circuit when the relay is activated; the circuit is connected when the relay is inactive

(3) $\mathrm{CO}$ or double-throw (DT), contacts control two circuits: one normally-open contact and one normally-closed contact with a common terminal.

This switching unit consists of a transistors (BC547BP) operating as a switch, relays and a DC motor. A simple example of relay switching unit where a $12 \mathrm{~V}$ DC circuit can be used to turn on/off a $230 \mathrm{~V}$ as shown in figure 2 . The working of the relay for various test conditions as shown in table1.

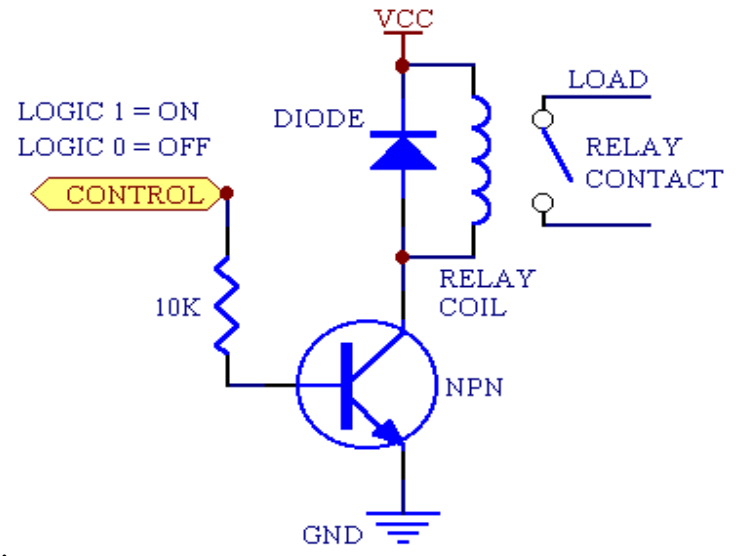

To implement the final bit of the automated irrigation system an electric motor (240VAC) was selected as the water pump. The first two units of the system i.e. sensing unit and the control unit (microcontroller) are powered by 5V DC. To interface the two units a 5V DC relay (SLT73-5D-1Z) was used as the isolation unit. The microcontroller was connected to the relay via an NPN transistor (BC547BP). To protect the transistor; while turning it on, a resistor of $470 \Omega$ is used. The resistor limits the current flowing through the transistor. To protect the microcontroller from back e.m.f during switching a diode was connected across the relay.

Table 1:Operation of relay for various moisture conditions

\begin{tabular}{|c|c|c|c|c|c|c|c|}
\hline$S / N$ & $\begin{array}{l}\text { Voltage } \\
\text { range }\end{array}$ & $\begin{array}{c}\text { Soil } \\
\text { condition }\end{array}$ & Q & $\begin{array}{l}\text { Amplifier } \\
\text { output } \\
\text { (digital) }\end{array}$ & $\begin{array}{c}\text { Relay } \\
\text { reference } \\
\text { pin voltage }\end{array}$ & $\begin{array}{l}\text { Relay } \\
\text { 'N0' } \\
\text { contact }\end{array}$ & $\begin{array}{l}\text { Water } \\
\text { pump } \\
\text { operation }\end{array}$ \\
\hline 1 & $>5 \mathrm{~V}$ & Excess wet & 0 & 1 & 1 & Open & $\mathrm{OFF}$ \\
\hline \multirow[t]{2}{*}{2} & \multirow{2}{*}{$\begin{array}{l}<5 \mathrm{~V} \& \\
>3 \mathrm{~V}\end{array}$} & $\begin{array}{c}\text { Optimally } \\
\text { Wet }\end{array}$ & 0 & 1 & 1 & Open & $\mathrm{OFF}$ \\
\hline & & $\begin{array}{c}\text { Optimally } \\
\text { Dry }\end{array}$ & 1 & 0 & 0 & closed & ON \\
\hline 3 & $<3 \mathrm{~V}$ & Dry & 1 & 0 & 0 & closed & ON \\
\hline
\end{tabular}

The deficiency of water in the field is sensed by the op-amp based sensor. Whenever there is need of water in the particular field, the high signal ("1") appears on the output pin of the sensor of that particular field. The output pins of all the sensors are connected to the PORT 2 of microcontroller. The high signal (logic 1 ) from the sensor is entertained by the microcontroller at a particular pin. By knowing the position of the pin on which signal appears, the microcontroller rotates the water funnel type cup at the desired speed by using DC motor connected at PORT 0 in clockwise direction. \& switch ON the RELAY (i.e. Water pump) connected at port 0 . Now water starts flowing into the required field. After completion of watering the sensor sends low signal (logic 0) to microcontroller. When microcontroller receives this signal, it switches OFF the water pump \& rotates the stepper motor in anticlockwise direction to the previous angle to bring the funnel cup in its initial position. Now microcontroller starts sensing the signal at PORT 2. Whenever there is signal at any pin the microcontroller repeats the above process. So this process continues \& we get the automatic irrigation the fields by using intelligent device microcontroller 8051. The schematic diagram as shown in figure 3

Figure 2: Relay Interfacing 


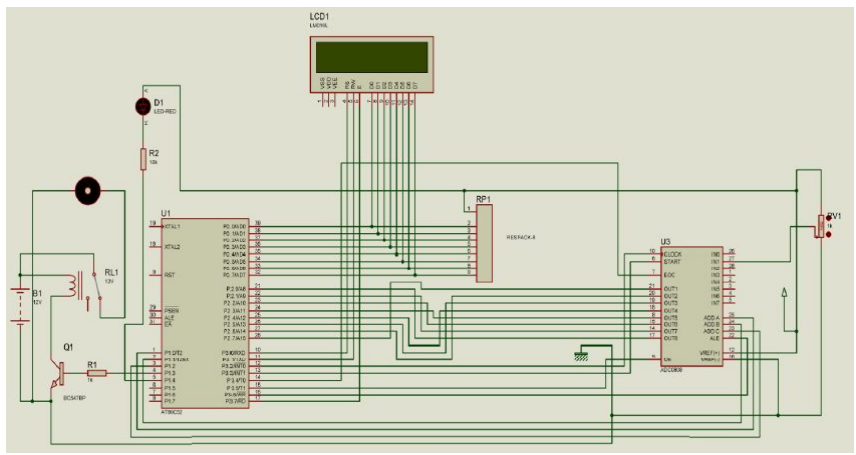

Figure 3: Schematic Diagram

Hardware model have been simulated using the software Proteus ISIS to verify the required result. Proteus allows engineers to run interactive simulations of real designs for circuit simulation. It has a range of simulator models for popular micro-controllers and a set of animated models for related peripheral devices such as LED and LCD displays, keypads and more. It is possible to simulate complete micro-controller systems and thus to develop the software for them without access to a physical prototype. The complete flow diagram as shown in figure 4.

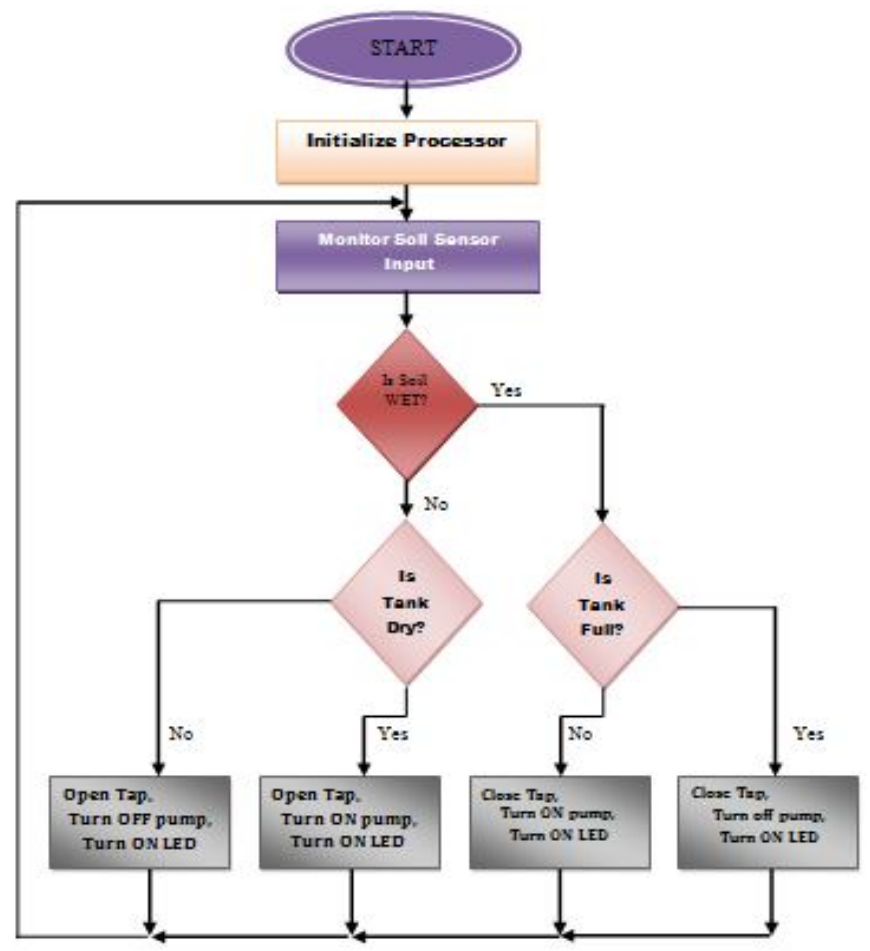

Figure 4: Flow Diagram

\section{RESULT AND DISCUSSION}

This deals with the description of tests performed on the various sections of the overall system and their corresponding results as well as the result of the overall system. In order to verify the correct functionality of the system, each component had to be tested individually. The testing was done on each and every components/sections that make up the circuit to ensure proper and satisfactory operation of the safe lock. The debugging was done using the Keil $\mu$ Vision 3 software and Proteus LAB simulation software; Each and every section of the code was debugged properly to ensure proper functionality thus a step debugging was done. This is a facility in the IDE for microcontroller and Proteus LAB simulation software that enables the step into program and at the same time views the registers and flag settings.

The system consists of Soil Moisture Sensor, a Microcontroller and a Relay interface board. The irrigation system consists of lanes through which each segment of the land is flooded and the flooding is controlled using valves as shown in the figure 5 . There is also a motor pump that is used to fill the water Tanker. The power supply unit of $+5 \mathrm{~V}$ and $+12 \mathrm{~V}$ were tested for the output voltage under no-load and full-load conditions.

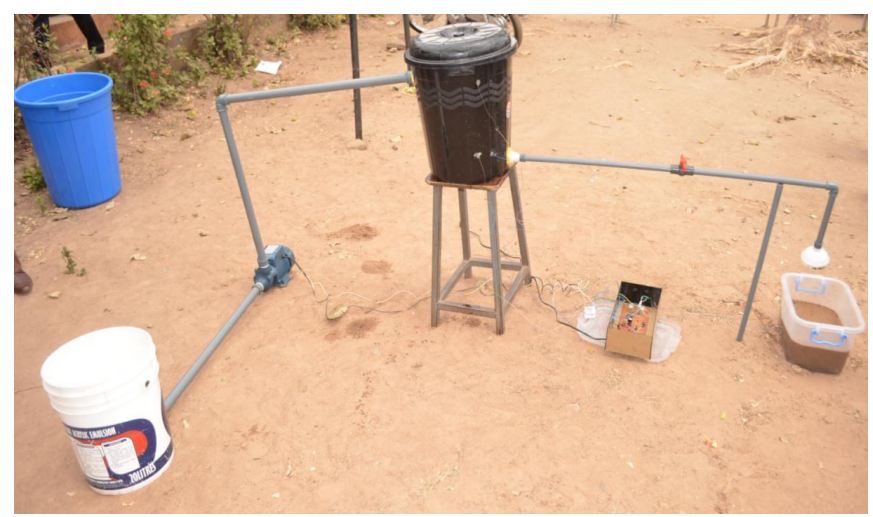

Figure 5: Experimental Set up of the system

In Soil condition analysis the VWC of sand soil, red soil and black soils were calculated. The raw data collected from the soil moisture sensor was recorded. The soil was measured in equal amount of 250 grams. Water was added in the soils in steps and the sensor values recorded. Figure 6 shows the graph of soil water content against sensor reading.

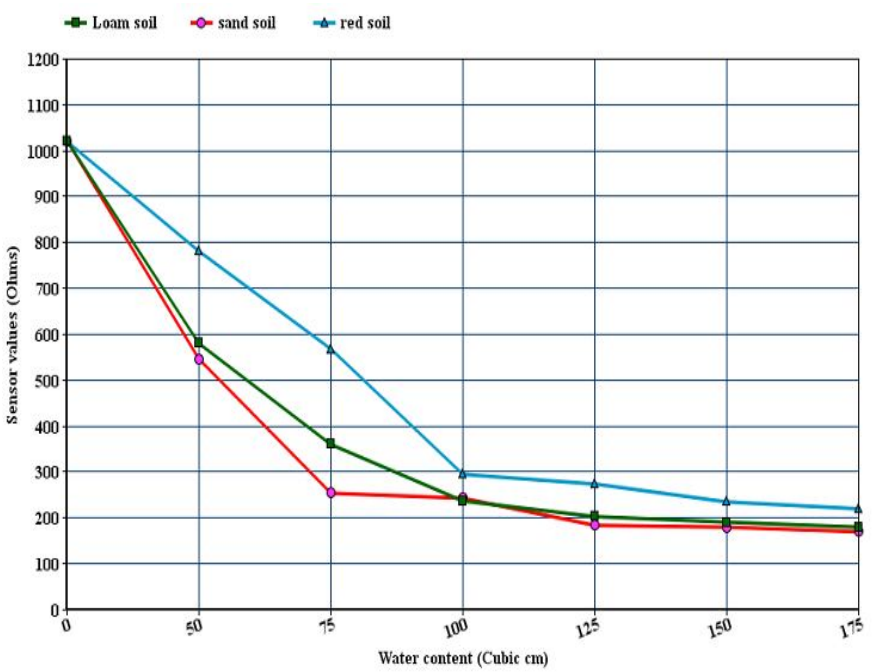

Figure 6: Soil condition analysis 
Amit Gangopadhyay, International Journal of Emerging Trends in Engineering Research, 9(7), July 2021, 994 - 998

From this graph it is seen that the value of the soil resistance decreases with increase in water content to a certain point Initially the three soils were dried using a frying pan until all the moisture content removed. 250 grams was measured for the red soil, black soil and the sand soil. Water was added in steps of $25 \mathrm{~cm}^{3}$ and sensor value recorded. The value of soil sensor at dry soil was almost equal for black soil, sand soil and red soil respectively. On adding $50 \mathrm{~cm}^{3}$ the resistance value reduced drastically to the range of 500. On adding more water the resistance value kept reducing. At around $100 \mathrm{~cm}^{3}$ of water the reduction on the soil resistance stated reducing at a much lower rate. This is because at this point the soil is now becoming saturated with water and thus adding more water has a small effect on the soil resistance. The sensor was calibrated and three states defined. The states are soggy, moist and dry. When the dry state was achieved the control unit (micro controller) switched the water pump on via a relay circuit. The three states were indicated using three different LEDs and an LCD. The LCD also indicated when the pump was running. The control circuit and the sensor circuit were powered using a $9 \mathrm{~V}$ alkaline battery which was connected via a voltage regulator with an output of $5 \mathrm{~V}$.

Thus it is seen that if the moisture level is found to be below the desired level, the moisture sensor sends the signal to the microcontroller which triggers the Water Pump to turn ON and supply the water to respective plant using the valve. When the desired moisture level is reached, the system halts on its own and the Water Pump is turned OFF. Thus, the functionality of the entire system has been tested thoroughly and it is seen that the function has successfully completed.

\section{CONCLUSION}

The proposed system has been found to be feasible and cost effective for optimizing water resources for agriculture production. The system has been tested to function automatically. Regular maintenance of the irrigation system is not required This system can be adjusted to variety of crops and improve the maintenance. The system is feasible for all type of crops. It can be used for large scale up green house and open field.

\section{REFERENCES}

1. Karan Kansara, Vishal Zaveri, Shreyans Shah, Sandip Delwadkar, Kaushal Jani, Sensor based Automated Irrigation System with IOT: A Technical Review, International Journal of Computer Science and Information Technologies, Vol.6, pp-5331-5333, 2015.

2. Shiraz Pasha B.R., Dr. B Yogesha, Microcontroller Based Automated Irrigation System, The International Journal Of Engineering And Science, Vol.3, pp- 06-09, June 2014.

3. S. R. Kumbhar, Arjun P. Ghatule, Microcontroller based Controlled Irrigation System for Plantation, Proceedings of the International MultiConference of
Engineers and Computer Scientists, Volume II, March 2013,pp-1-4.

4. Srilikhitha, M. M. Saikumar, N. Rajan, M. L. Neha and M. Ganesan, Automatic irrigation system using soil moisture sensor and temperature sensor with microcontroller AT89S52, International Conference on Signal Processing and Communication (ICSPC), 2017, pp- 186-190.

5. Jerry John Kponyo, Kwasi Adu-Boahen Opare, Ahmed Abdul-Rahman, Justice Owusu Agyemang An Intelligent Irrigation System for Rural Agriculture International Journal of Applied Agricultural Sciences Vol. 5,pp- 75-81, 2019.

6. V Madhu, V Viswanadha Automated Irrigation System Using WSN\& GSM Module International Journal of Emerging Trends in Engineering Research , Vol. 3 No.6, Pages : 207- 211 , June 2015.

7. Mamta Patidar, S.S.Belsare Design and Implementation of Automatic Irrigation System using ARM7 International Journal of Electrical Electronics and Data communication, Special Issue-1, pp-51-53, 2015.

8. Nema, M.K., Khare, D., Chandniha, S.K., Application of artificial intelligence to estimate the reference evapotranspiration in sub-humid Doon valley, Appl Water Sci. Vol.7,pp-3903-3910, 2017

9. A.G. El-Naggar, C.B. Hedley, D. Horne, P. Roudier, B.E. Clothier, Soil sensing technology improves application of irrigation water, Agricultural Water Management, vol. 228, Feb, 2020.

10. M.Priyadharshini, U.M.Sindhumathi, S.Bhuvaneswari, N.Rajkamal, K.M.Arivu Chelvan Automatic Irrigation System using Soil Moisture Sensor with Bigdata International Journal of Engineering Trends and Technology Vol.67, pp- 58-61,2019..

11. Utiérrez, J., Medina, J.F.V., Garibay, A.N., Gándara, M.A.P. Automated Irrigation System Using a Wireless Sensor Network and GPRS Module. IEEE Transactions on Instrumentation and Measurement. Vol.63(1), pp-1-11,2014

12. J. L. Bhaskar, B. Koli, P. Kumar and V. Gaur, Automatic crop irrigation system, IEEE 4th International Conference on Reliability Infocom Technologies and Optimization,Sep, 2015,pp-1-4..

13. Abdurrahman Mehamed, Ahmed Gebremedhn, Mehari Gebru and Tsigabu Teame Bezabih, Sensor Based Automatic Irrigation Management System, International Journal of Computer and Information Technology, Vol.4, pp- 2279-0764, May 2015.

14. Sumeet. S. Bedekar, Monoj. A. Mechkul, and Sonali. R.Deshpande IoT based Automated Irrigation System, International Journal for Scientific Research\& Development, Vol. 3, pp-1015-1018, May 2015. 